\title{
3
}

\section{MEANING MAKING IN THE DUAL PROCESS MODEL OF COPING WITH BEREAVEMENT}

\author{
MARGARET S. STROEBE AND HENK SCHUT
}

In the following passage from War and Peace, Tolstoy described reactions to the death of Prince Andrei:

When the body, washed and clothed, lay in the coffin on the table everyone went to take leave of him, and everyone wept.

Little Nikolai cried because his heart was torn with perplexity. The countess and Sonya cried from pity for Natasha and because he was no more. The old count cried because he felt that before long he too must step over the same terrible threshold.

Natasha and Princess Maria wept too now, but they wept not because of their own personal grief: they wept from the emotion and awe which took possession of their souls before the simple and solemn mystery of death that had been accomplished before their eyes. 
It is evident from this passage that reactions to the loss of the prince differed according to the specific meaning attached to the death by each of the bereaved people present: To say that everyone cried because they were grief stricken emerges as a gross oversimplification. Everyone cried, but for very different reasons.

How a person feels and reacts on becoming bereaved is dependent on the meaning that is assigned to the loss. Although this seems intuitively convincing - even a truism - and well demonstrated in such literary accounts, the problem remains that "meaning" is a nebulous concept. If it is so central, then to understand the phenomena associated with bereavement we need to define meaning in a scientifically useful way. Furthermore, we need to empirically operationalize and examine component parts of the concept.

Different scientific approaches reflecting differing theoretical positions have been adopted to elucidate "meaning" in research on bereavement. For example, attachment perspectives (e.g., Bowlby, 1980) have examined the nature (meaning) of the relationship with the deceased person. Family systems theorists (e.g., Nadeau, 1998) have examined processes of meaning making in families. The sociologist Tony Walter (1996) has addressed meaning-related themes in his "New model of grief," wherein the construction of biography about the deceased person becomes a central process in grieving. Social support theorizing (e.g., W. Stroebe \& Stroebe, 1987) has analyzed the meaning of loss in terms of the deficits (emotional, companionship, instrumental, appraisal, etc.) created by the death of the significant person. Cognitive stress theorists (e.g., Folkman \& Lazarus, 1980; Lazarus \& Folkman, 1984) have focused on appraisal processes in dealing with stressors such as bereavement and the relation of these to coping and adjustment. The psychosocial transition model (Parkes, 1993) defined specific psychological and social aspects of loss and gain that are concomitant with bereavement. Similarly, Rubin's (1992) two-track model can be regarded as defining categories of meaning. Finally, cognitive therapists (e.g., Fleming \& Robinson, 1991) have provided analyses in terms of attributions and cognitive processing.

None of these perspectives offers an analysis of the dynamics of cognitive processing within the framework of a bereavement-specific model of coping. We need to understand what types of cognitions bereaved people are going through and how these are regulated across the course of time: What categories of meaning are used, and how do these change to enable the bereaved person to progress through grief and come to terms with loss? The purpose of this chapter is to provide an exploration of such cognitive processes, using the framework of the dual process model of coping with bereavement (DPM; for a more detailed description of the basic model, see M. Stroebe \& Schut, 1999). This analysis of the process of coping with bereavement focuses specifically on the aspect of confrontation and avoid- 
ance, the positive and negative valence of the emotion or situation being confronted or avoided, and its effects on coping with loss.

\section{STRUCTURAL COMPONENTS OF THE DPM}

The DPM provides an analytic framework for understanding how people adapt to the loss of a significant person in their lives. Earlier theoretical formulations and principles of intervention emphasized the centrality of grief work in this process (e.g., Bowlby, 1980; Freud, 1917/1957; Lindemann, 1944; Raphael \& Nunn, 1988). The so-called "grief work hypothesis" that can be derived from these perspectives states that people need to confront their loss, to go over the events before and at the time of death, to focus on memories, and to work toward detachment from the deceased person. Fundamental is the view that one needs to bring the reality of loss into one's awareness as much as possible and that suppression is maladaptive. Recently, following questions raised at the theoretical level (e.g., Rosenblatt, 1983; Stroebe, 1992; Wortman \& Silver, 1987) and failures to verify it empirically (e.g., M. Stroebe \& Stroebe, 1991; Wortman \& Silver, 1987, 1989 ), bereavement researchers have come to realize the potential limitations inherent in the grief work hypothesis. Although grief work is seen as an integral part of coming to terms with loss, other processes need consideration. Thus, although the DPM incorporates the grief work principle it extends conceptualization of the manner in which adaptation takes place in the following way.

The DPM specifies two types of stressors: loss orientation and restoration orientation. This specification is necessary because research has shown that bereaved people not only have to cope with the loss of the loved person himself or herself, but also have to make major adjustments in their lives that come about as secondary consequences of the death. Both of these aspects are potential sources of stress and anxiety. Loss-oriented coping thus refers to dealing with, concentrating on, and working through some aspect of the loss experience itself (e.g., crying about the death, yearning for the person, looking at his or her photograph). Restoration-oriented coping, on the other hand, includes mastering of the tasks that the bereaved person had undertaken, dealing with arrangements for reorganizing life, and developing new identities.

It is important to make this specification with respect to stressors, first, because it enables us to define meaning accordingly. For example, loss-oriented coping would involve dealing with such cognitions (meanings) as "I miss his presence every minute of the day," whereas an example of restoration-oriented meaning would be "I am a single person in a 'couple' society." Second, although the two types of stressor are interrelated, one cannot simultaneously attend to both: Coping at any one point in time is either loss 
or restoration oriented. The bereaved individual can, in fact, to some extent choose to ignore or to concentrate on the one or the other aspect of loss and change in their lives. Thus, it becomes necessary to introduce a regulatory process, which we have designated oscillation. Oscillation is a dynamic process, fundamental to adaptive coping, of alternation between loss- and restoration-oriented coping and alternation between coping with one of these two stressors and not coping at all (complete distraction, unrelated daily activities). Confrontation of loss is, then, interspersed, for example, with avoidance of memories or attendance to the additional stressors such as managing extra household chores or dealing with the changed finances. These basic components of the model are depicted in Figure 3.1.

\section{COPING STRATEGIES IN THE DPM}

The process of coming to terms with the loss of a loved person emerges as more complex than described in grief work formulations. Grief work is indeed part of grieving - at least within our own Western, industrialized culture. It does seem that one needs to focus on grief in order to assimilate the experience into pre-existing schemas or change the schemas to accommodate to the changed world (cf. Janoff-Bulman, 1992). Repetition, rumination or-arguably most important - sharing with others who would help change schemas would seem necessary. But this-following the DPM-is not enough. How can we define the more complex cognitive processes underlying the structure outlined in this model? What dimensions are relevant for the analysis of coping with bereavement, and how can we describe the mechanisms that influence the course of adjustment? Answers to these questions should bring us closer to describing ways to analyze meanings of loss and to examine the role that such cognitions may have in the process of adjustment to bereavement. Some leads can be found in the cognitive stress literature. Theorists in this field have identified major types of coping strategies, including emotion-focused versus problem-focused coping and the confrontation-avoidance dimension (e.g., Billings \& Moos, 1981; Lazarus \& Folkman, 1984; for a review, see de Ridder, 2000).

As discussed elsewhere (M. Stroebe \& Schut, 1999), the emotionproblem-focused dimension is not equivalent to but cuts across loss- and restoration-oriented coping. For example, restoration-oriented coping differs from problem-focused coping, even though the former is defined in terms of secondary problems. It subsumes emotion-focused coping associated with managing the secondary life stressors, such as mastering the skills lost with the deceased person, which could be tackled either by trying out the task or by working on one's anxiety about accomplishing the skills (e.g., through distraction, avoidance, and emotional control). For such reasons, the problem-emotion-focused coping dimension is not considered useful for further analysis in this context. 


\section{A Dual Process Model of Coping With Bereavement}

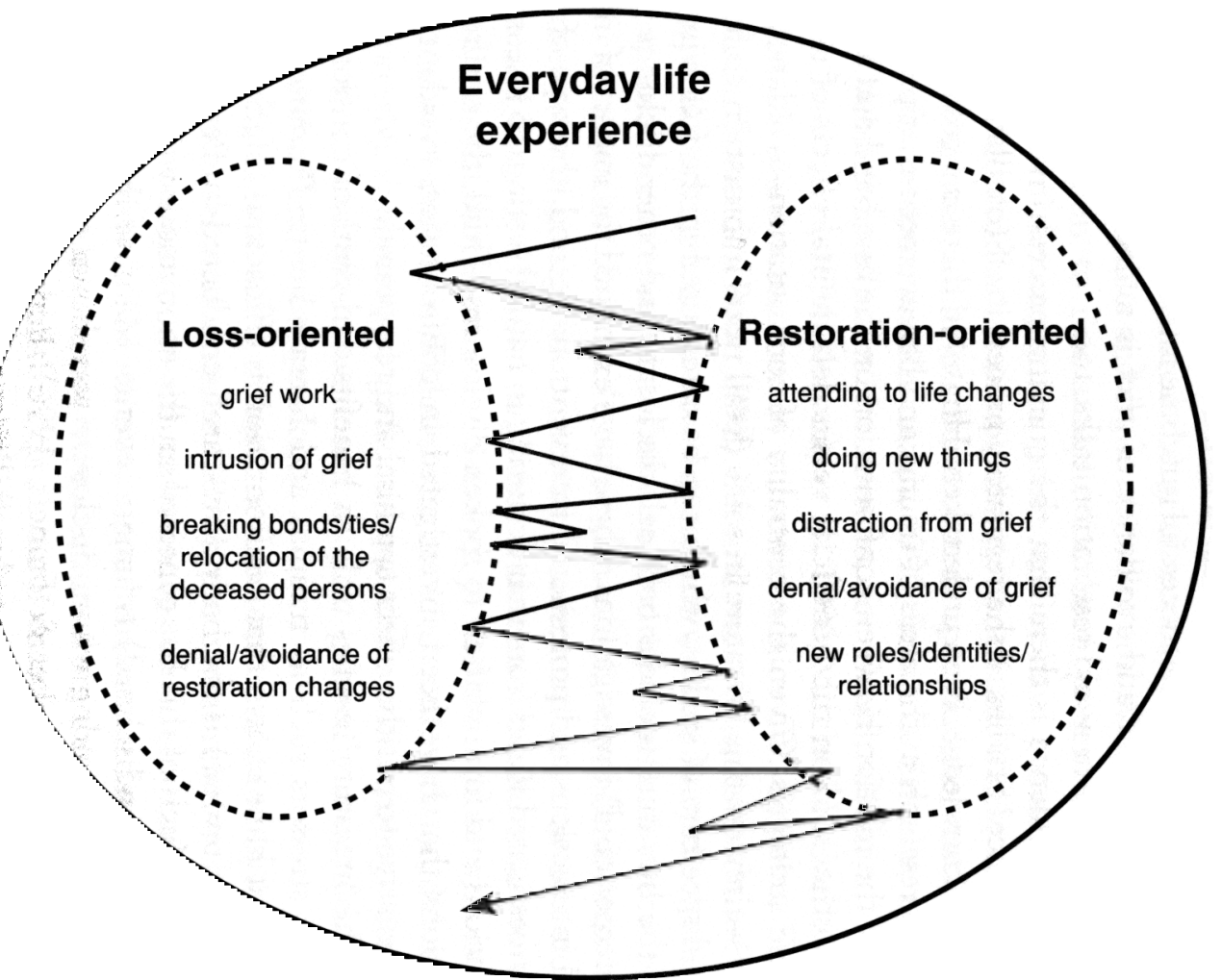




\section{Confrontation-Avoidance Coping Dimension}

By contrast, the confrontation-avoidance dimension is applicable. It is evident that, conceptually, grief work and confrontation overlap. It would be impossible to do grief work without confrontation. What the grief work concept does not incorporate, however, is an analysis of the dynamic processing of confrontation versus avoidance of specific aspects of loss, as stipulated in the DPM. Furthermore, the model describes the necessity of oscillation, that is, a regulatory process, for successful outcome rather than claiming that confrontation is adaptive and avoidance of grief is maladaptive. Furthermore, one can confront or avoid restoration tasks, too.

What evidence is there that the grieving process involves confrontation-avoidance? Studies of the regulatory process itself (oscillation) have not yet, to our knowledge, been undertaken. However, there is a growing body of empirical research in the areas of trauma and bereavement that provides evidence of the relation between confrontation on the one hand and avoidance on the other and on the beneficial versus detrimental effects of using one of these strategies. Given the centrality of confrontation-avoidance in the DPM, we review this literature in some detail next. Information comes from a broad spectrum of studies, which can be categorized in the following ways: First, the literature includes both self-disclosure and other-disclosure (intravs. interpersonal) investigations. These have examined the impact of informal social interactions and professional intervention. Second, the type of disclosure investigated varies from that occurring in natural settings to research manipulations and from written to spoken disclosures. Third, the nature of the cognitions that have been investigated in confrontation-avoidance range from negative to positive affect appraisal and reappraisal.

The literature testifies to both benefits and costs of confronting and avoiding stressors such as traumas and bereavements. Prominent among studies that have shown that confrontation is efficacious (cf. Smyth, 1998, for a recent review) is the body of research conducted by Pennebaker and colleagues. Much of this has centered on the anonymous written disclosure of (previously undisclosed) traumatic events. Many of the studies involve student samples, among whom disclosure was shown to improve academic performance (Pennebaker \& Francis, 1996). Pennebaker also found that writing about stressful events reduced illness-related consultations with doctors (Pennebaker \& Beall, 1986; Pennebaker, Kiecolt-Glaser, \& Glaser, 1988) and boosted immune system resilience (Pennebaker et al., 1988; Petrie, Booth, Pennebaker, Davison, \& Thomas, 1995). The effects of these manipulations were strong and consistent, leading Pennebaker to probe for causal mechanisms underlying the deleterious effects of emotional inhibition (Pennebaker, 1989). In the past few years, the focus has been on the role of language (through structuring, assimilating, imposing of meaning, etc.) in the disclosure process (Pennebaker, 1993; Pennebaker \& Francis, 
1996). Some replications and extensions of this type of research have been conducted by others. Greenberg and Stone (1992) showed the health benefits of writing about traumas, as did Murray, Lamnin, and Carver (1989), who found therapy - thus, verbal communication - even more helpful than writing.

Although the above-mentioned studies produced clear-cut results supportive of the grief work hypothesis, others have been far less so, suggesting that confrontation is not (always) efficacious. The early work of Wortman and Silver $(1987,1989)$ refuted the grief work hypothesis on the basis of their own empirical results and those of Parkes and Weiss (1983). An alternative interpretation to this analysis has been presented elsewhere (cf. Stroebe, 1992). In the meantime, other studies have provided support for the view that confrontation is not always beneficial. These come from a wide range of sources, including bereavement-specific intervention efficacy assessment (for reviews, see Kavanagh, 1990; Schut \& Stroebe, 1997) and studies of debriefing efficacy (for reviews, see Deahl, Gillham, Thomas, Searle, \& Srinivasan, 1994; Kenardy et al., 1996; Mitchell \& Everly, 1995).

Illustrative are a number of our own studies (W. Stroebe, Stroebe, Schut, Zech, \& van den Bout, 1997). We and our colleagues used the Pennebaker type of paradigm in an investigation of written diary disclosure following spousal bereavement but failed to identify beneficial effects of this type of confrontation. In a further study, in which respondents were asked about their way of going about grieving (confrontation vs. avoidance), M. Stroebe and Stroebe (1991) found that widowers who did grief work had better adjustment scores over an 18-month period than those who avoided confrontation of their loss. Widows who avoided confrontation did not differ in depressive symptomatology from those who worked through their loss. Thus, the beneficial effects were not as clear generally as would be concluded from the Pennebaker results.

In a longitudinal study of bereaved spouses conducted by Schut, van den Bout, de Keijser, and Stroebe (1996), the causal relation between the expression of emotions and health outcome (psychological/somatic symptomatology) was analyzed. The measure tapped emotional discharge as well as social sharing. Again in contrast to predictions from the grief work hypothesis, the results showed that the expression of emotions was almost entirely independent of outcome scores: Whether one did or did not express one's grief had little impact on recovery.

Along slightly different lines, Rimé and his colleagues in Louvain, Belgium, have concentrated on verbal disclosure-or social sharing, as they have termed it. Their studies have investigated patterns of sharing following a wide variety of situations through which nonclinical samples have gone, from giving birth, to bungee jumping, to watching a horror film, to bereavement (e.g., Rimé, Mesquita, Philippot, \& Boca, 1991; Rimé, Philippot, Boca, \& Mesquita, 1992; Rimé, Finkenauer, Luminet, Zech, \& Philippot, 1998). 
The sharing of highly emotional events is very frequent but, again in contrast to the Pennebaker findings, the amount of social sharing did not show a clear relation to recovery over time from the emotional impact of the event.

Other studies have examined the functions of avoidance. Bonanno, Keltner, Holen, and Horowitz (1995) provided evidence that avoidant strategies may be more functional than had previously been assumed in the bereavement literature. Using a longitudinal strategy, Bonanno et al. found a dissociation between physiologically measured arousal and indexes of psychological upset among bereaved men who were placed in an "empty chair" situation. High physiological arousal, but low psychological confrontation, were associated with good outcome (measured at a later time). Thus, whereas too complete a denial has frequently been associated with pathological forms of grieving (e.g., Jacobs, 1993), Bonanno et al.'s study suggests that some degree of avoidance may be healthy (see also Bonanno \& Keltner, 1997).

Kelly and McKillop (1996) reviewed studies on the benefits of keeping secrets, ones in which the secret keeper was directly involved. Contrary to the large literature testifying to the advantages of revealing personal secrets, they provided evidence to show that choosing to reveal secrets is very complex and may have disturbing consequences (e.g., being rejected, alienated from the listener), including the emergence of a negative self-image. Not all secrets should be revealed, and not indiscriminately, to just anybody, it appears.

Kaminer and Lavie (1993) even showed the benefits of denial over confrontation among people who have endured extremely traumatic experiences. These researchers studied survivors of the Holocaust in Israel, who could be expected to have had multiple bereavements as well as the experience of lasting trauma. In order to study the survivors' long-term adaptation, Kaminer and Lavie focused on sleep and dreams, comparing difficulties and disturbances among well-adjusted versus less well-adjusted survivors. The higher the intrusion of Holocaust-related memories and complaints and distress in everyday life, the more disturbed was the sleep, and the higher the dream recall. Well-adjusted survivors had lower recall of dreams than nonHolocaust control survivors. Kaminer and Lavie argued that the massive repression of dream content is an adaptive mechanism. Assisting traumatized survivors to repress the terrors of the past may have more adaptive value than "working through" strategies.

Taken together, the results reported above appear discrepant, with some studies indicating beneficial effects, and others detrimental effects, of confrontation or of avoidance. How can these apparent discrepancies be explained? A range of stressors has been investigated. It must be recognized that the nature of the experiences associated with some traumas are different from some bereavements, such that disclosing or confronting has very different implications. For example, a trauma may not have been shared before because of secret, stigmatizing, inhibition-related or nonsharable aspects (e.g., one may not want to burden others with horrendous images). 
Rimé et al. (1998) recently described a similar phenomenon in their "threshold for sharing" idea. Loss of an attachment figure, by contrast, is frequently not horrific or secret. Many of the studies induced confrontation or disclosure. In cases where a bereavement is not also traumatic it is also likely that there is occurrence of "natural" sharing, that is, that there has already been confrontation with, and cognitive processing of, the death (cf. Rimé et al., 1998). The manipulation would not be expected to have a significant impact in such cases. It is also possible that the manipulation is sometimes not strong enough to yield discernible consequences.

\section{Analysis of Cognitions Related to Confrontation-Avoidance}

It is evident that we need to define precisely what is being confronted or avoided. What cognitive expressions (meanings) versus nonexpressions are associated with good versus poor outcome? The key to understanding who will adjust well to bereavement and who will not lies in the analysis of cognitions associated with confrontation-avoidance.

Two lines of empirical research are useful in an analysis of cognitions. On the one hand, research has been conducted on the relation between the impact of (expression/confrontation of) negative affect and well-being; on the other hand, research has addressed the impact of positive feelings and well-being. First we describe the research findings. Then we examine pathways within the coping process. Finally, we relate this research to the DPM, providing a framework for incorporating "meaning" into the analysis of coping with bereavement.

\section{Rumination in Confrontation With Loss}

According to our analysis, studies that have shown confrontation to have detrimental effects on adjustment (e.g., Wortman \& Silver, 1987, 1989) are those in which the confrontation is associated with negative affect. People whose style is to confront and talk about negative, distressing aspects of their loss a lot or who, in studies in which disclosure is forced, talk to investigators about distressing things to do with loss, over time do not do as well as those who refrain (more) from this type of disclosure. It is evident that disclosure versus nondisclosure has to be shown to be a predictor and not just a corollary of adjustment. A few studies have indeed controlled for the amount of distress at the outset of the evaluation and thus provide information on the potential impact of the disclosure on later recovery.

Nolen-Hoeksema, Parker, and Larson (1994) reported disadvantages of ruminative ways of going about coping with bereavement. They defined ruminative coping as thoughts and behaviors that focus attention on symptoms of distress and the meanings and consequences of these symptoms. It is also defined as repetitive and passive, not active, problem solving. Examples of self-focused responses to depressed mood are "I think "Why do I react this 
way?" "and "I think back to other times I have been depressed," whereas symptom-focused responses would include such thoughts as "I think about how hard it is to concentrate." Possible consequences and causes of mood are illustrated in the following: "I think 'I won't be able to do my job if I don't snap out of this'" and "I go away by myself and think about why I feel this way."

People with a ruminative style early in bereavement were found to have higher depression levels 6 months later (when depression level at Time 1 was controlled for). Those with a more distractive style became less depressed over time. Bereaved women were found to ruminate more than did bereaved men.

Capps and Bonanno (in press) provided further evidence of such processes. They used a narrative analysis procedure-a carefully developed coding system to evaluate the type, valence, and intimacy of the narratives. How does this predict grief, distress, and somatic symptoms over time? Sixmonth measurements were compared with those taken at 14 months and 25 months. Disclosure of negatively valanced emotions predicted increased distress and somatic complaints.

\section{Positive Feelings in Confrontation With Grief}

Along similar lines, it has recently been shown that disclosing or otherwise confronting positive aspects associated with loss leads to recovery. Again, the same stringent methodological requirements, with baseline controls, and longitudinal designs as outlined for the studies on negative affect reviewed above, are necessary for an adequate test of the mediating role of positive affect in recovery.

Foremost in this research has been the work of Folkman and her colleagues. Folkman has conducted a large-scale prospective study of the effects of caregiving and bereavement among partners of men with AIDS. The study included self-report and clinical observation both during the time leading up to and following the death of a partner (see Folkman, Chesney, Collette, Boccellari, \& Cooke, 1996; Folkman, Chesney, Cooke, Boccellari, \& Collette, 1994). Despite harrowing and extremely exhausting circumstances, it was found that, in addition to negative emotional states, these men experienced positive emotions through their caregiving and bereavement.

Folkman also has examined types of coping that had to do with the search for and finding of positive meaning (positive reappraisal, goaldirected problem-focused coping, spiritual beliefs and practices, and the infusion of ordinary events with positive meaning). These were associated with positive psychological states during bereavement. She carried out quantitative analyses of longitudinal data. (For a review, see Folkman, in press.) Of importance here is the result that positive appraisal and problem-focused coping were significantly and independently associated with positive affect, 
when positive affect for the previous month and for the other seven types of coping on the Ways of Coping Checklist were controlled for (see Moskowitz, Folkman, Collette, \& Vittinghoff, 1996). In line with this, path analysis of the spiritual beliefs measure, positive reappraisal, and positive affect showed that spirituality facilitated positive reappraisal of the difficult situation and that the latter, in turn, helped support positive psychological states.

This suggests that being able to find positive meaning in bereavementrelated stressful events brings about or enhances positive affect, that being able to interpret positively is effective in creating a positive state of mind and, presumably, in reducing distress. Positive psychological states emerge as part of the coping process. This study (Folkman, 1997) suggests the need to focus on these positive states of mind in addition to focusing, as in the past, on coping with distress.

Support for this pattern comes from studies conducted by Bonanno and colleagues. In the narrative analysis study described earlier (Capps \& Bonanno, in press), more frequent disclosure of positive thoughts predicted decreased grief. In a further analysis of this data set, Keltner and Bonanno (1997) investigated laughter and smiling - similarly looking for predictors of good adjustment over time. Duchenne laughter (which involves the action of the orbicularis oculi muscle and is interpreted as a genuine smile) was found to be related to self-reports of reduced anger, increased enjoyment, dissociation of distress, and better social relations.

The implication of the above reasoning is that positive psychological states are integral to the coping process itself. In other words, positive emotions can actually help one to cope with bereavement; they are part of the grieving process. They are not just "off-setting" emotions that occur in relation to the cessation of an aversive condition (cf. Folkman, 1997). Not only does one "feel good while feeling bad" but one also "feels good to make one feel less bad"—even "feels less bad by feeling good" (cf. Folkman, 1997, in press). How does this analysis supersede previous understanding? It does so in two important ways: It states that it is not just that positive states coexist with depression (e.g., Wortman \& Silver, 1992) or that blocking negative information and creating positive illusions enhances mental and physical health (Taylor, 1989). By designing a longitudinal study, and controlling for the level of distress and symptomatology at the first point of measurement, Folkman (1997) was able to show not only an association but also the predictive strength of positive thoughts, just as this was done with respect to negative thoughts in the research of Nolen-Hoeksema et al. (1994).

\section{Pathways to (Mal)Adjustment}

Following the above lines of research, we suggest that ruminating about a loss will worsen grief and depression, whereas positive appraisal of aspects associated with the loss experience will do the opposite, supporting 
the adjustment process. The next question to address, then, is how this comes about. How does rumination operate to lengthen and worsen grief and positive appraisal to ameliorate it?

With respect to rumination, Nolen-Hoeksema and Jackson (1996) argued that it first enhances the effects of depressed mood on thinking. Their research showed that people who engaged in ruminative coping when they were distressed would think more negatively about their current situation and their life in general. Second, it interferes with everyday instrumental behaviors. These people were less motivated to participate in everyday activities that raise feelings of well-being and give a sense of control. Third, it interferes with good problem solving. They were less effective in using interpersonal problem-solving skills. Nolen-Hoeksema's analysis of ruminative coping was applied to depressed mood in general. Her naturalistic studies included samples of bereaved people. It would seem fair to infer that these three pathways-the enhancing effect of negative mood on thinking, the interference with instrumental behavior, and the interference with effective problem solv. ing-also apply more specifically to the lengthening and worsening of grief.

The pathways whereby Folkman (1997) integrated positive psychological states into a model of coping were threefold. First, meaning-based processes (e.g., positive reappraisals) lead to positive psychological states. Second, negative psychological states may motivate people to search for and create positive psychological states in order to gain relief (coping as a response to distress). Third, positive psychological states lead back to appraisal and coping, and coping efforts are sustained.

An example, taken from Chuang Tzu, China, third century B.C., illustrates the ways that positive affect and appraisal can lead to adjustment:

When first she died, how could I not help being affected? But then, on examining the matter, I saw that in the Beginning she had originally been formless. And not only formless, but she had originally lacked all substance. During this first state of confused chaos, there came a change which resulted in substance. This substance changed to assume form. The form changed and became alive. And now it has changed again to reach death. In this it has been like the passing of the four seasons, spring, summer, autumn, and winter. And while she is thus lying asleep in the Great House (i.e. the Universe), for me to go about weeping and wailing, would be to show myself ignorant of Fate (ming). Therefore I refrain.

Finding existential meaning would be an example of the impact of positive reappraisal. The motivation to search, the second pathway, is also clearly illustrated and, with respect to the third, perhaps one could say that the positive affect created by the reappraisal was the next step in the chain to being able to cope with the loss of the loved one, enabling a continuation of refrainment from grief because of the peaceful state of mind that had been achieved. 
How do (a) confrontation versus avoidance of positive and negative states and (b) the pathways to enhancement versus amelioration of grief fit into the DPM? There are good reasons to argue the need for oscillation between positive and negative affect/(re)appraisal as an integral part of the coping process, just as was argued above for the fluctuation between attention to loss and restoration-oriented stressors. Persistent negative affect intensifies grief, yet working through grief, which includes rumination, is the essence of coming to terms with a bereavement. Positive reappraisals, on the other hand, sustain the coping effort, yet if positive psychological states are maintained relentlessly, grieving is neglected. Alternation between these psychological states emerges as essential.

Folkman (1997) recently integrated positive meaning states into a revision of stress-coping theory, which can be incorporated into the dual process formulation. In accordance with the line of argument above, also needed is integration of negative appraisals. This can be done by introducing pathways as shown in Figure 3.2. Oscillation between positive and negative affect and (re)appraisal facilitates and provides pathways whereby one can cope with the different dimensions of grieving.

To illustrate: Riches and Dawson (1998) explored the manner in which photographs can provide opportunities for parents to remember the life (as opposed to the death) of their deceased child. This may facilitate conversations and reminiscences about the living relationship and enable introduction of the deceased child to people who did not know him or her (this frequently occurred in our own interviews with bereaved parents). Photographs can assist the development of the ongoing narrative about the deceased child and can be searched for meaning, furthering the process of coming to terms with the fact of loss and the reality of the child's life. Riches and Dawson described an interview with a couple who lost their teenage daughter Vicki quite suddenly. Photograph albums were drawn out, as the conversation turned to her life, and Vicki's mother, who had not wanted to take active part in the interview before, became as involved in the conversation as her husband. In the authors' words,

The tenor of the interview noticeably shifted from the story of their distress at Vicki's death and of their feelings immediately following it, to a growing expression of pride in her achievements and immense fondness for the life they had lived together. For a short while, photographs taken on school trips, family outings and holidays, stories that recalled her personal idiosyncrasies and her strength of character, and pieces of work she had written and drawn (especially the neatness of her geography folder with its meticulously drawn maps and perfect handwriting) allowed Sheila and Peter to "browse" through her life, celebrating the fact of her existence and identifying those features that best characterized 


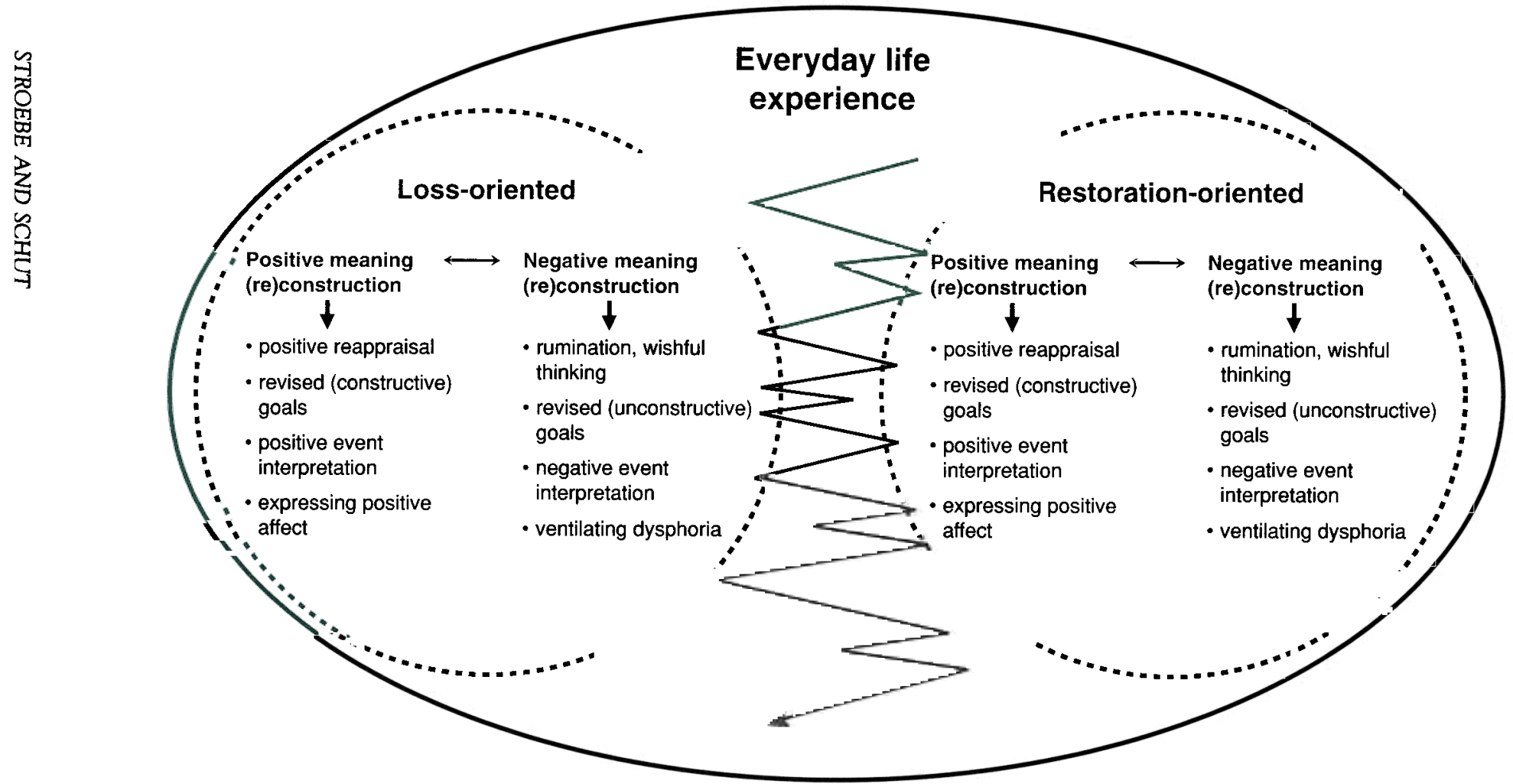

Figure 3.2. A dual process model of coping with loss: Pathways. Jagged arrow represents oscillation. 
her. By the end of the interview, I had come to "know" Vicki and had a sense of the presence which Sheila and Peter retained. (Riches \& Dawson, 1998, pp. 133-134)

The shift from confrontation of negative affect associated with the shock of the death to positive ones relating to Vicki's life and achievements are evident, as are the implications for struggling on with the identity of bereaved parents. It is not hard to imagine how such photographic memories, sporadically dwelt on, help to regulate the cognitive processing of affect associated with loss and restoration tasks.

\section{CONCLUSION}

In the words of Robert Neimeyer (cf. the Introduction to this volume), needed in our field of study is an understanding of bereavement that recognizes the fundamental revision of assumptive worlds, meaning systems, or life narratives. The effort must be to move toward an appreciation of grieving as a process whereby we effortfully and idiosyncratically reconstruct a world of meaning and restore coherence to the narratives of our lives (cf. Neimeyer, Keesee, \& Fortner, 2000). The analysis of loss and restoration orientation, the underlying negative and positive cognitions associated with each of these dimensions, and the process of oscillation between these components provide a framework for a systematic probing of assumptive worlds, meaning systems, and life narratives. Basic to the conceptualization of grief is that it is dynamic, fluctuating, and changing over time. It also lends itself to appreciation of idiosyncrasies (there is no single "correct" way to grieve).

The task now is to provide empirical verification for the DPM. Until this has been done we must, of course, be cautious in deriving practical implications from assumed regularities: Supportive evidence has been described for component parts of the model, demonstrating first the positive and negative consequences of confronting and of avoiding both loss and restoration tasks of grieving and, second, the impact of positive and negative psychological (re)appraisals and states of mind in confrontation-avoidance of the various aspects. What remains to be examined empirically is the process itself of oscillation between these components.

\section{REFERENCES}

Billings, A. G., \& Moos, R. H. (1981). The role of coping responses and social resources in attenuating the stress of life events. Journal of Behavioral Medicine, 4, 139-157.

Bonanno, G. A., \& Keltner, D. (1997). Facial expressions of emotion and the course of conjugal bereavement. Journal of Abnormal Psychology, 106, 126-137. 
Bonanno, G. A., Keltner, D., Holen, A., \& Horowitz, M. J. (1995). When avoiding unpleasant emotions may not be such a bad thing: Verbal-autonomic response dissociation and midlife conjugal bereavement. Joumal of Personality and Social Psychology, 69, 975-989.

Bowlby, J. (1980). Attachment and loss: Vol. 3. Loss: Sadness and depression. London: Hogarth.

Capps, L., \& Bonanno, G.A. (in press). Narrating bereavement: Thematic and grammatical predictors of adjustment to loss. Discourse Processes, 30.

Deahl, M. P., Gillham, A. B., Thomas, J., Searle, M. M., \& Stinivasan, M. (1994). Psychological sequelae following the Gulf War: Factors associated with subsequent morbidity and the effectiveness of psychological debriefing. British Journal of Psychiatry, 165, 60-65.

de Ridder, D. (2000). Gender, stress, and coping: Do women handle stressful situations differently from men? In L. Sher \& J. S. St. Lawrence (Eds.), Women, health and the mind (pp. 155-135). Chichester, UK: Wiley.

Fleming, S. J., \& Robinson, P. (1991). The application of cognitive therapy to the bereaved. In M. Vallis, J. Howes, \& P. C. Miller (Eds.), The challenge of cognitive therapy: Applications to nontraditional populations (pp. 135-158). New York: Plenum.

Folkman, S. (1997). Positive psychological states and coping with severe stress. Social Science \&8 Medicine, 45, 1207-1221.

Folkman, S. (in press). Revised coping theory and the process of bereavement. In M. S. Stroebe, R. O. Hansson, W. Stroebe, \& H. Schut (Eds.), Handbook of bereavement research: Consequences, coping, and care. Washington, DC: American Psychological Association.

Folkman, S., Chesney, M. A., Collette, L., Boccellari, A., \& Cooke, M. (1996). Post bereavement depressive mood and its pre-bereavement predictors in HIV+ and HIV - gay men. Journal of Personality and Social Psychology, 70, 336-348.

Folkman, S., Chesney, M. A., Cook, M., Boccellari, A., \& Collette, L. (1994). Caregiver burden in HIV+ and HIV - partners of men with AIDS. Journal of Consulting and Clinical Psychology, 62, 746-756.

Folkman, S., \& Lazarus, R. S. (1980). An analysis of coping in a middle-aged community sample. Journal of Health and Social Behavior, 21, 219-239.

Freud, S. (1957). Mourning and melancholia. In J. Strachey (Ed. \& Trans.), The standard edition of the complete psychological works of Sigmund Freud (Vol. 14, pp. 239-260). London: Hogarth Press. (Original work published 1917)

Greenberg, M. A., \& Stone, A. A. (1992). Emotional disclosure about traumas and its relation to health: Effects of previous disclosure and trauma severity. Journal of Personality and Social Psychology, 63, 75-84.

Jacobs, S. (1993). Pathologic grief: Maladaptation to loss. Washington, DC: American Psychiatric Press.

Janoff-Bulman, R. (1992). Shattered assumptions: Towards a new psychology of trauma. New York: Free Press.

Kaminer, H., \& Lavie, P. (1993). Sleep and dreams in well-adjusted and less adjusted Holocaust survivors. In M. Stroebe, W. Stroebe, \& R. O. Hansson 
(Eds.), Handbook of bereavement: Theory, research and intervention (pp. 331345). New York: Cambridge University Press.

Kavanagh, D. G. (1990). Towards a cognitive-behavioral intervention for adult grief reactions. British Joumal of Psychiatry, 157, 373-383.

Kelly, A. E., \& McKillop, K. J. (1996). Consequences of revealing personal secrets. Psychological Bulletin, 120, 450-465.

Keltner, D., \& Bonanno, G. A. (1997). A study of laughter and dissociation: Distinct correlates of laughter and smiling during bereavement. Journal of Personality and Social Psychology, 73, 687-702.

Kenardy, J. A., Webster, R. A., Lewin, T. J., Carr, V. J., Hazell, P. L., \& Carter, G. L. (1996). Stress debriefing and patterns of recovery following a natural disaster. Journal of Traumatic Stress, 9, 37-49.

Lazarus, R., \& Folkman, S. (1984). Stress, appraisal and coping. New York: Springer.

Lindemann, E. (1944). Symptomatology and management of acute grief. American Joumal of Psychiatry, 101, 141-148.

Mitchell, J. T., \& Everly, G. S. (1995). Critical incident stress debriefing (CISD) and the prevention of work-related traumatic stress among high risk occupational groups. In G. S. Everly \& J. M. Lating (Eds.), Psychotraumatology (pp. 269-280). New York: Plenum.

Moskowitz, J., Folkman, S., Collette, L., \& Vittinghoff, E. (1996). Coping and mood during AIDS-related caregiving and bereavement. Annals of Behavioral Medicine, 18, 49-57.

Murray, E. J., Lamnin, A. D., \& Carver, C. (1989). Emotional expression in written essays and psychotherapy. Journal of Social and Clinical Psychology, 8, 414-429.

Nadeau, J. W. (1998). Families making sense of death. Thousand Oaks, CA: Sage.

Neimeyer, R., Keesee, N., \& Fortner, B. (2000). Loss and meaning reconstruction: Propositions and procedures. In R. Malkinson, S. Rubin, \& E. Witztum (Eds.), Traumatic and non-traumatic bereavement. Madison, CT: Psychosocial Press.

Nolen-Hoeksema, S., \& Jackson, B. (1996, August). Ruminative coping and the gender differences in depression. Paper presented at the 104th Annual Convention of the American Psychological Association, Toronto, Ontario, Canada.

Nolen-Hoeksema, S., Parker, L. E., \& Larson, J. (1994). Ruminative coping with depressed mood following loss. Journal of Personality and Social Psychology, 67, 92-104.

Parkes, C. M. (1993). Bereavement as a psychosocial transition: Processes of adaptation to change. In M. Stroebe, W. Stroebe, \& R. O. Hansson (Eds.), Handbook of bereavement: Theory, research and intervention (pp. 91-101). New York: Cambridge University Press.

Parkes, C. M., \& Weiss, R. (1983). Recovery from bereavement. New York: Basic Books.

Pennebaker, J. (1989). Confession, inhibition and disease. In L. Berkowitz (Ed.), Advances in experimental social psychology (Vol. 22, pp. 211-244). New York: Academic Press.

Pennebaker, J. (1993). Putting stress into words: Health, linguistic, and therapeutic implications. Behavior Research and Therapy, 31, 539-548. 
Pennebaker, J., \& Beall, S. (1986). Confronting a traumatic event: Toward an understanding of inhibition and disease. Journal of Abnormal Psychology, 95, 274281.

Pennebaker, J., \& Francis, M. (1996). Cognitive, emotional, and language processes in disclosure. Cognition $\mathcal{B}$ Emotion, 10, 601-626.

Pennebaker, J., Kiecolt-Glaser, J. K., \& Glaser, R. (1988). Disclosure of traumas and immune function: Health implications for psychotherapy. Journal of Consulting and Clinical Psychology, 56, 239-245.

Petrie, J., Booth, R., Pennebaker, J., Davison, K., \& Thomas, M. (1995). Disclosure of trauma and immune response to a hepatitis $B$ vaccination program. Journal of Consulting and Clinical Psychology, 65, 789-792.

Raphael, B., \& Nunn, K. (1988). Counseling the bereaved. Journal of Social Issues, 44, 191-206.

Riches, G., \& Dawson, P. (1998). Lost children, living memories: The role of photographs in processes of grief and adjustment among bereaved parents. Death Studies, 22, 121-140.

Rimé, B., Finkenauer, C., Luminet, O., Zech, E., \& Philippot, P. (1998). Social sharing of emotion: New evidence and new questions. In W. Stroebe \& M. Hewstone (Eds.), European review of social psychology (Vol. 9). Chichester, England: Wiley.

Rimé, B., Mesquita, B., Philippot, P., \& Boca, S. (1991). Beyond the emotional event: Six studies on the social sharing of emotion. Cognition $\mathscr{E}$ Emotion, 5, $435-465$.

Rimé, B., Philippot, P., Boca, S., \& Mesquita, B. (1992). Long-lasting cognitive and social consequences of emotion: Social sharing and rumination. In W. Stroebe \& M. Hewstone (Eds.), European review of social psychology (Vol. 3, pp. 225258). Chichester, England: Wiley.

Rosenblatt, P. (1983). Bitter, bitter tears: Nineteenth century diarists and twentieth century grief theories. Minneapolis: University of Minnesota Press.

Rubin, S. (1992). Adult child loss and the two-track model of bereavement. Omega, 24, 183-202.

Schut, H., \& Stroebe, M. (1997, June). Does help help? Paper presented at the International Conference on Grief and Bereavement, Association for Death Education and Counseling, Washington, DC.

Schut, H., van den Bout, J., de Keijser, J., \& Stroebe, M. (1996). Cross-modality grief therapy: Description and assessment of a new programme. Journal of Clinical Psychology, 52, 357-365.

Smyth, J. (1998). Written emotional expression: Effect sizes, outcome types, and moderating variables. Journal of Consulting and Clinical Psychology, 66, 174184.

Stroebe, M. (1992). Coping with bereavement: A review of the grief work hypothesis. Omega, 26, 19-42.

Stroebe, M., \& Schut, H. (1999). The dual process model of coping with bereavement: Rationale and description. Death Studies, 23, 197-224. 

itroebe, M., \& Stroebe, W. (1991). Does "grief work" work? Journal of Consulting
and Clinical Psychology, 59, 479-482.

itroebe, W., \& Stroebe, M. (1987). Bereavement and health. New York: Cambridge

troebe, W., Stroebe, M., Schut, H., Zech, E., \& van den Bout, J. (1997, June). Must we give sorrow words? Paper presented at the Third International Conference on Grief and Bereavement in Contemporary Society, Washington, DC. aylor, S. E. (1989). Positive illusions: Creative self perception and the healthy mind.
New York: Basic Books.

'alter, T. (1996). A new model of grief: Bereavement and biography. Mortality, 1,

'ortman, C. B., \& Silver, R. C. (1987). Coping with irrevocable loss. In G. R. VandenBos \& B. K. Bryant (Eds.), Cataclysms, crises and catastrophes: Psychology in action (pp. 189-235). Washington, DC: American Psychological Asso-

ortman, C. B., \& Silver, R. C. (1989). The myths of coping with loss. Journal of Consulting and Clinical Psychology, 57, 349-357.

rrtman, C. B., \& Silver, R.C. (1992). Reconsidering assumptions about coping with loss: An overview of current research. In L. Montada, S. H. Filipp, \& Hillsdale, NJ: Erlbaum. 